\title{
Stabilization of Butyrylcholinesterase by the Entrapment into the Natural Polymer-Based Gels
}

\author{
V. I. Lonshakova-Mukina", E. N. Esimbekova"- * *, and V. A. Kratasyuk"* \\ Presentedby Academician I. I. Gitelson September 4, 2017
}

\begin{abstract}
A new method for obtaining stable butyrylcholinesterase (BuChE) samples based on the enzyme immobilization in starch and gelatingels followed by drying is proposed. Coimmobilization of Bu ChE with the thiol group indicator 5,5'-dithiobis(2-nitrobenzoic) acid did not reduce the activity of BuChE, which allowed us to simplify the procedure and reduce the time of analysis of organophosphorus pesticides. The resulting immobilized samples retained activity for at least 300 days. Bu ChE samples based on the starch gel showed a greater sensitivity in the determination of pesticides as compared to the samples based on the gelatin gel.
\end{abstract}

The high sensitivity and selectivity of methods for determination of substances using enzymes deter 7 mines their wide use as analytical systems for rapid analysis of the degree of pollution of ecosystems of various complexity [1-3]. However, currently the enzymatic methods of control of environmental objects are not widely used in practice. This is associated primarily with the problem of providing the sta $\urcorner$ bility of enzyme preparations (namely, retention of the analytical signal value at elevated temperatures, extreme $\mathrm{pH}$ values, etc.) rather than with the lack of regulations of their use [4]. To use enzymes in methods of environmental bioassays and assessment of the quality of water, air, and soil more widely, it is necessary to obtain reagents that combine stability during storage and use and sensitivity to inhibitors of enzymes at the level of their maximum permissible concentrations.

Among the inhibitors of enzyme that are important for the analytical control of the environment, organophosphorus pesticides occupy a special place. Their use in large amounts led to heavy pollution of a num ber of ecosystems. The toxicity of most of them for homoiothermal animals and the maintenance of relatively high concentrations of pesticides in the environ 7 ment pose a potential danger to humans and require

\footnotetext{
Siberian Federal University, Krasnoyarsk, 660041 Russia Institute of Biophysics, Siberian Branch, Russian Academy of Sciences, Federal Research Center, Krasnoyarsk Research Center, Siberian Branch of the Russian Academy

of Sciences, Krasnoyarsk, 660036 Russia

*e-mail:esimbekova@yandex.ru
}

the development of rapid methods to control their content. For example, butyrylcholinesterase $(\mathrm{BuChE})$, an enzyme of the class of hydrolases, along with acetylcholinesterase is widely used in inhibitor analysis, including the analysis of organophosphorus pesticides [5]. This analysis is based on the change in the $\mathrm{BuChE}$ activity in the presence of pesticides, which is proportional to their content in the test sample. The most common method used to determine the activity of $\mathrm{BuChE}$ in the presence of pesticides is the method of Ellman [6]. Butyrylcholinesterase hydrolyzes sub strate butyrylthiocholine to thiocholine and butyric acid. Thiocholine reacts with 5'5-dithio-bis(2-nitrobenzoic) acid (Ellman's reagent) to form yellow 2nitro-5-thiobenzoic acid, the formation rate of which is directly proportional to the enzyme activity.

The most common method to preserve activity and, therefore, to increase the stability of $\mathrm{BuChE}$ is its immobilization on different types of substrates. Today, more than 40 ways to immobilize $\mathrm{BuChE}$ are known [7]. In most cases, the cross-linking of the enzyme with glutaraldehyde in the presence of an inert protein is used [8]. Recently, the methods of $\mathrm{BuChE}$ entrapment in organized surface layers (Langmuir-Blodgett films) [9] and the physical adsorption of the enzyme in agarose gel with the addition of silicon nanoparticles are becoming increasingly popular [10]. When the last two immobilization methods are used, the enzyme remains accessible for interaction with an inhibitor. However, all these methods do not allow coimmobilization of $\mathrm{BuChE}$ with other components of the analytical system for the determination of $\mathrm{BuChE}$ activity, which complicates the experimental procedure. The methods of entrapment of the enzyme in polysiloxane, 


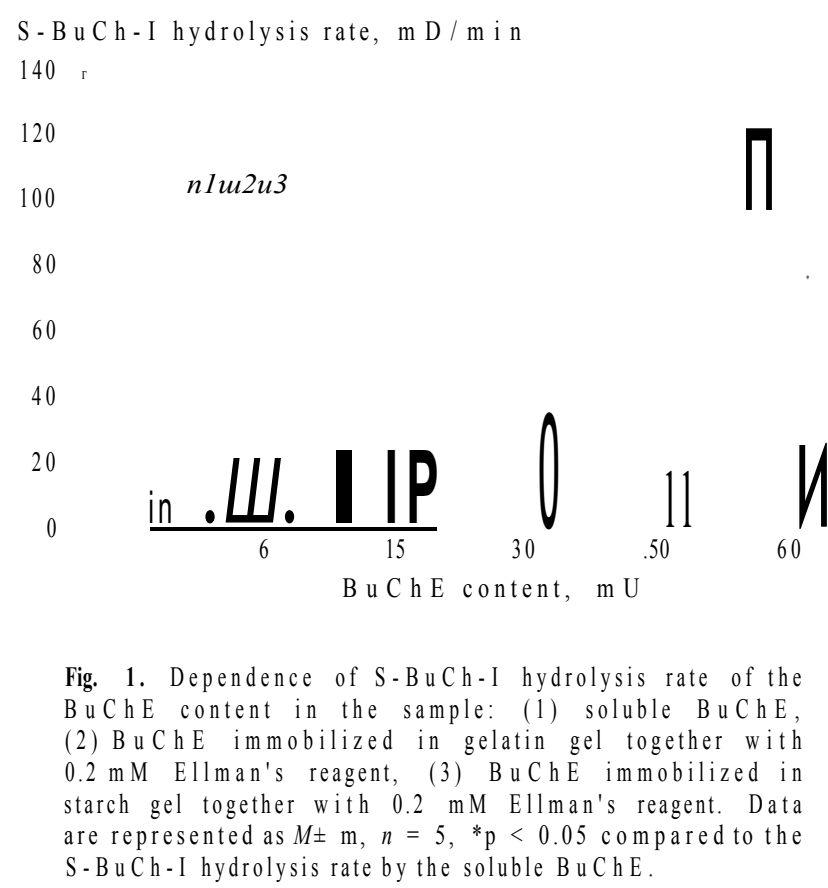

vinyl pyrrolidone, and starch gels are devoid of this drawback [11, 12].

The goal of this study was to obtain multicomponent $\mathrm{BuChE}$ samples stable during storage and use. To achieve this goal, we coimmobilized BuChE with 5-5'-dithiobis(2-nitrobenzoic) acid in gelatin and starch gels with subsequent drying.

In this study, we used freeze-dried horse serum BuChE (Sigma-Aldrich, United States) with activity of $15003 \mathrm{ncat} / \mathrm{mg}$. S-butyrylthiocholine iodide was used as a substrate, and Ellman's reagent (SigmaAldrich) was used as an indicator of thiol groups. The activity of $\mathrm{BuChE}$ was determined as the rate ofhydrolysis of substrate S-butyrylthiocholine iodide ( $\mathrm{mD} / \mathrm{min}$, mU of optical density per minute) in potassium phosphate buffer $(0.05 \mathrm{M}, \mathrm{pH}$ 7.9) containing $4 \mathrm{mM}$ Ellman's reagent. The reaction yields a yellow anion, whose formation is recorded spectrophotometrically at a wavelength of $412 \mathrm{~nm}$ [6]. Immobilization of enzymes and Ellman's reagent in starch and gelatin gels was performed as described in [13]. The resulting sample was a dried disk 6-7 $\mathrm{mm}$ in diameter (dry weight, $1.5 \pm 0.2 \mathrm{mg}$ ). Each experimental point was the result of at least three measurements. Data were statistically processed using Student's $t$ test. Differences were considered significant at $p<0.05$.

In this study, we compared the activity of $\mathrm{BuChE}$ in the soluble form and $\mathrm{BuChE}$ immobilized together with Ellman's reagent in starch and gelatingels. As can be seen in Fig. 1, when gelatin and starch gels were used as a support for immobilization, there was no substantial loss of $\mathrm{BuChE}$ activity during coimmobilization with $0.2 \mathrm{mM}$ Ellman's reagent. Therefore, both

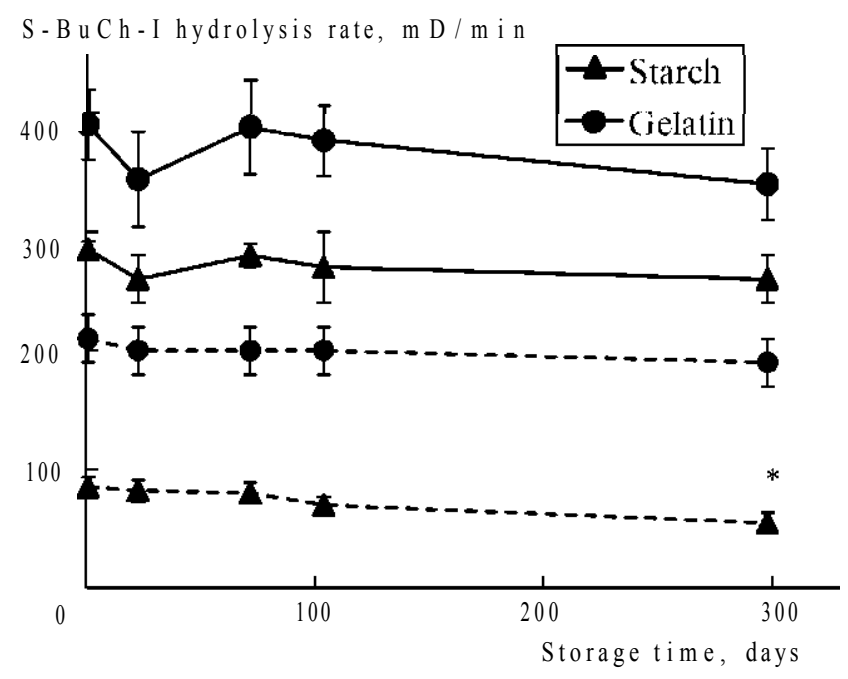

Fig. 2. Dependence of the $\mathrm{S}-\mathrm{BuCh}-\mathrm{I}$ hydrolysis rate in a buffer solution (solid line) and in distilled water (dashed line) on the storage time. Data are represented as $M \pm \mathrm{m}$, $n=5,{ }^{*} p<0.05$ compared to the S-BuCh-I hydrolysis rate at the initial time.

gels can be used to provide a high yield of activity of the immobilized enzyme sample.

In addition to high activity, an important charac teristic of enzyme sample is its storage stability. We found that the samples based on BuChE coimmobilized with the Ellman's reagent can be stored for a long time without loss of activity. For example, the activity of the samples containing 1.83 ncat $\mathrm{BuChE}$ and $0.2 \mathrm{mM}$ Ellman's reagent did not change during storage at $4^{\circ} \mathrm{C}$ for 300 days (Fig. 2). This stabilizing effect is determined by the spatial constraints that arise when the enzyme is entrapped into gels and prevents the modification of the native structure of the enzyme.

Immobilized enzyme samples can exhibit activity when distilled water is used instead of buffer (Fig. 2). Despite the fact that the activity of the enzymes in dis tilled water is reduced 2 or 3 times (depending on the nature of the gel), the fact that the enzyme activity is retained in distilled water is very important for further use of these samples in bioassays. It means that these enzyme preparations can be used for analysis by the classical method (i.e., by determining the level of safe sample dilution).

It is worth noting that the gelatin gel-based samples had a higher activity and retained their activity during storage to a greater extent as compared to the starch gel-based samples. We found that the gelatin gel-based sample containing 1.83 ncat $\mathrm{BuChE}$ and $0.2 \mathrm{mM}$ indicator, the $\mathrm{S}-\mathrm{BuCh}-\mathrm{I}$ hydrolysis rate was $30 \%$ higher compared to the starch gel-based sample (Fig. 2). These differences may be due to different mechanisms of the enzyme stabilization in polysaccharide and polypeptide gels. 
Residual activity, \%

1201

100

80

60

40

20

0

$\begin{array}{llllllll}0.005 & 0.010 & 0.020 & 0.050 & 0.980 & 2.440 & 15.300\end{array}$ Pirimiphos-methyl, mg/L

100 $*$

80

60

40

20

$\begin{array}{llllllll}0 & 0.001 & 0.002 & 0.008 & 0.016 & 0.160 & 1.600^{\mathrm{j}} \frac{\mathrm{i}}{1} \frac{\mathrm{i}}{\mathbf{i}} \frac{\mathbf{i}}{00}\end{array}$ Malathion, mg/L

Fig. 3. Dependence of the residual activity of the samples of B u ChE coimmobilizedwith the Ellman's reagent in the starch gel in the presence of inhibitors (a) pirimiphos methyl and (b) malathion. Data are represented as $M \pm \mathrm{m}$, $n=5,{ }^{*}$ p $<0.05$. Inhibitor concentrations were 10 wer than the maximum permissible concentrations.

Next, using malathion and pirimiphos-methyl as an example, we estimated the sensitivity of $\mathrm{BuChE}$ coimmobilized with the Ellman's reagent to the inhib itory effect of organophosphorus compounds (OPCs). We determined the dose-effect dependence, which was then used to determine the $\mathrm{IC}_{20}$ and $\mathrm{IC}_{5_{0}}$ values (i.e., effective inhibitor concentrations reducing $\mathrm{BuChE}$ activity by 20 and $50 \%$, respectively). To increase the sensitivity of the samples to $O P C s$, the samples were preincubated in the test inhibitor solu tion for $5 \mathrm{~min}$

We found that the starch gel-based samples exhibited a higher sensitivity to OPCs. The I C s $_{0}$ value for malathion was $0.008 \mathrm{mg} / \mathrm{L}$, which is 6 times $10 \mathrm{wer}$ than the maximum permissible concentration (Fig. $3 a$ ). The addition of pirimiphos-methyl also reduced the activity of the immobilized $\mathrm{BuChE}$ (Fig. 3b). How ever, in this case, the $\mathrm{IC}_{2}$ value $(0.015 \mathrm{mg} / \mathrm{L})$ was close to the maximum permissible concentration for this compound $(0.01 \mathrm{mg} / \mathrm{L})$. The gelatin gel-based samples showed a $10 \mathrm{w}$ sensitivity to malathion and pirimiphos-methyl. This may be due to the high degree of stabilization of the enzyme by this substrate.

Thus, in this paper we described a method for obtaining butyrylcholinesterase samples that are stable during storage by entrapping the enzyme into natural polymer gels followed by drying. The addition of the
Ellman's reagent makes it possible to simplify the pro 7 cedure and reduce the time of analysis. The enzyme samples based on the starch gel exhibit a high sensitiv ity to organophosphorus compounds. Therefore, from the viewpoint of practical use of the developed immor bilized samples for the analytical control of OPCs in different samples, starch is the most suitable carrier.

\section{A C K N O W L E D G M E N T S}

The study was supported by the joint project of the Russian Foundation for Basic Research, the Govern 7 ment of the Krasnoyarsk krai, and the Krasnoyarsk Regional Foundation for Support of Scientific and Technological Activity no. 16-44-242126. This work was also partly supported by the state task for the basic research of the Russian Academy of Sciences (project no. 01201351504$)$.

\section{REFERENCES}

1. Luque de Castro, M.D. and Herrera, M.C., Biosens. Bioelectron., 2003, vol. 18, pp. 279-294.

2. Amine, A., Mohammadi, H., Bourais, I., and Palleschi, G., Biosens. Bioelectron., 2006, vo1.21, pp. 1405-1423.

3. Davis, F., Law, K.A., Chaniotakis, N.A., Fournier, D., Gibson, T., Millner, P., Marty, J.-L., Sheehan, M.A., Ogurtsov, V. I., Johnson, G., Griffiths, J., Turner, A.P.F., a nd Higson, S.P.J., Compr. Analyt. Chem., 2007, vol. 49, pp. 311-330.

4. Shekhovtsova, T. N., Muginova, S.V., and Veselova, I.A., Izv. Akad. Nauk, Ser. Khim., 2007, no. 7, pp. 583-597.

5. Evtyugin, G.A., Problemy analiticheskoi khimii. Otdelenie khimii $i$ nauk o materialakh RAN. Biokhimicheskie metody analiza (Problems of Analytical Chemistry. Department of Chemistry and Materials Science of the Russian Academy of Sciences. Biochemical Methods of Analysis), Moscow: Nauka, 2010, vol. 12.

6. Ellman, G.L., Biochem. Pharmacol., 1961, vol. 7, pp. $88-95$.

7. Andreescu, S. and Marty, J.-L., Biomol. Engin., 2006, no. 23, pp. $1-15$.

8. Il'icheva, N. Yu., Beilinson, R.M., Medyantseva, E.P., Budnikov, G.K., and Vanyagina, 0.N., Vestn. Mosk. Univ., Ser. 2: Khim., 2002, vol. 43, no. 6, pp. 409-412.

9. Wan, K., Chivelon, J.M., and Jaffrezic-Renault, N., Talanta, 2000, vol. 52, pp. 663-670.

10. Glenn, R.J. and Luckarift, H.R., Enzyme Stabilization and Immobilization. Enzyme Stabilization via Bio-Templated Silicification Reactions, United States, 2017.

11. Esimbekova, E.N., Lonshakova-Mukina, V.I., Bezrukikh, A.E., and Kratasyuk, V.A., Dokl. Biochem. Biophys., 2015, vol. 461, pp. 102-105.

12. Bezrukikh, A., Esimbekova, E., Nemtseva, E., Kratasyuk, V., and Shimomura, 0., Analyt. Bioanalyt. Chem., 2014, v01. 406, no. 23, pp. 5743-5747.

13. Esimbekova, E.N., Lonshakova-Mukina, V.I., and Kratasyuk, V.A., R F Patent no. 2546245, Byul. FIPS Izobreteniya. Poleznye modeli, 2015, no. 10.

Translated by M. Batrukova 